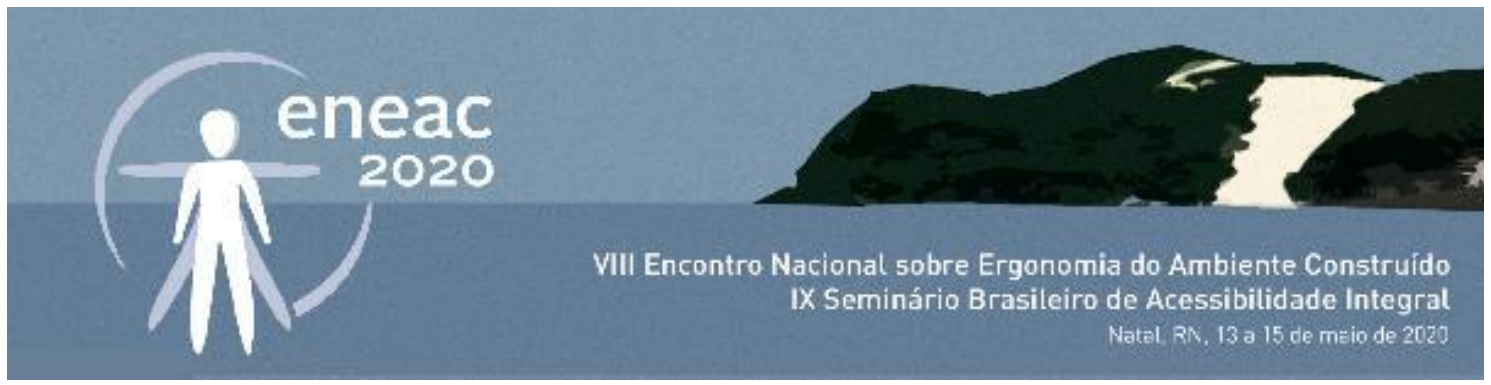

\title{
Rota acessível em centro universitário: proposta para o UNIESP
}

\author{
Accessible route in university centre: proposal for UNIESP
}

LUCAS NASCIMENTO LUSTOSA

Tecnólogo em Design de Interiores, bacharelando em Arquitetura e Urbanismo UNIESP

lucasnlustosa@hotmail.com

ANDERSON NATAN FERNANDES ESCARIÃO

Bacharel em Psicologia, Graduando em Design de Interiores UNIESP

natan.escariao25@gmail.com

LARISSA NASCIMENTO DOS SANTOS

Coordenadora do curso de Design de Interiores UNIESP, doutoranda em Design UFPE

larissansns@gmail.com

JÚLIO CÉSAR FELIX DE ALENCAR FERNANDES

Professor do curso de Design de Interiores UNIESP, doutorando em Design Universidade

de Aveiro, Portugal

Julio.interiores85@gmail.com

\begin{abstract}
RESUMO
Uma das formas de possibilitar um fácil acesso aos espaços físicos é utilizando uma rota acessível, que consiste em um trajeto contínuo, desobstruído e sinalizado, que conecta os ambientes externos e internos de espaços e edificações, e que pode ser utilizada de forma autônoma e segura por todas as pessoas (ABNT, 2015). Este artigo tem como objetivo apresentar os resultados parciais referente ao desenvolvimento de uma rota acessível no Centro Universitário de Educação Superior da Paraíba - UNIESP, com a intenção de possibilitar um percurso autônomo e seguro de qualquer pessoa, independente da sua restrição de mobilidade. Esta pesquisa está sendo executada pelo Laboratório de Acessibilidade e Ergonomia - LacErgo do UNIESP. Para a desenvolvimento desta, foram realizados levantamentos físicos e fotográficos, passeios acompanhados por pessoas com deficiência, análise de fluxo de pedestres, e por fim, a definição da melhor rota. Constatou-se que existe a real necessidade do atendimento aos parâmetros descritos pela norma brasileira de acessibilidade - NBR 9050 (ABNT, 2015). A depender da particularidade de cada edifício, a rota pode ser implantada sem grandes modificações, sobretudo onde há áreas livres, como foi o caso do objeto deste estudo.
\end{abstract}

PALAVRAS-CHAVE: rota acessível, centro universitário, acessibilidade, pessoa com deficiência. 


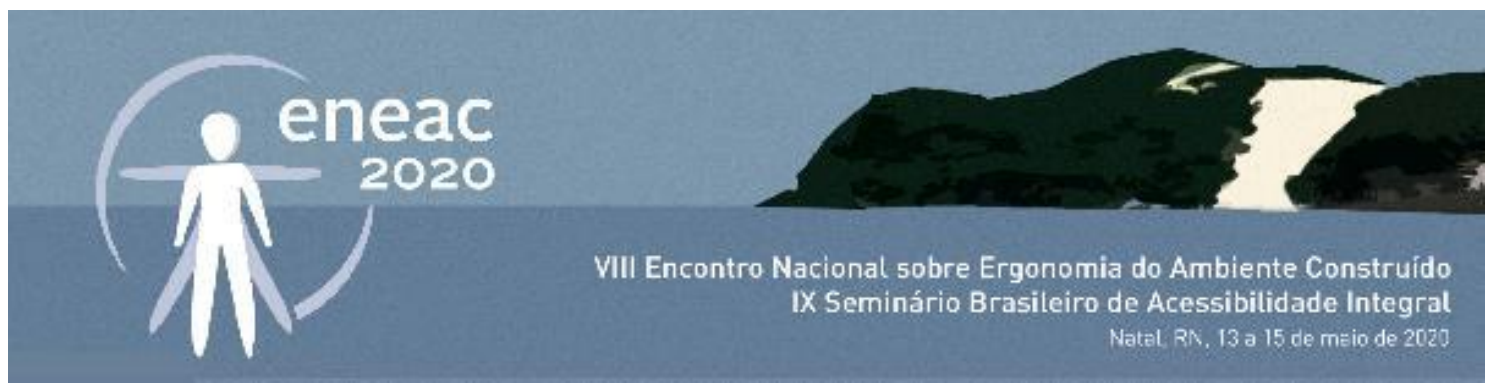

\section{ABSTRACT}

One of the ways to provide easy access to physical spaces is by using an accessible route, which consists of a continuous, unobstructed and signposted path that connects the external and internal environments of spaces and buildings, and can be used autonomously and safely by all people (ABNT, 2015). This article aims to present the partial results regarding the development of an accessible route at the Centro Universitário de Educação Superior da Paraiba-UNIESP, with the intention of making possible an autonomous and safe route for any person, regardless of their mobility restriction. This research is being carried out by the Laboratory of Accessibility and Ergonomics - LacErgo of UNIESP. For its development, physical and photographic surveys were carried out, walks accompanied by people with disabilities, pedestrian flow analysis, and finally, the definition of the best route. It was found that there is a real need to meet the parameters described by the Brazilian standard of accessibility - NBR 9050 (ABNT, 2015). Depending on the particularity of each building, the route can be implemented without major modifications, especially where there are free areas, as was the case of the object of this study.

KEYWORDS: accessible route, university centre, accessibility, disabled person.

\section{INTRODUÇÃO}

Em 2015 foi instituído o Estatuto da Pessoa com Deficiência, na forma da Lei de Inclusão da Pessoa com Deficiência. O capítulo IV desta lei se refere ao direito à educação, afirmando expressamente que a educação, em todos os níveis, é direito da pessoa com deficiência, e é dever do Estado, da família, da comunidade escolar e da sociedade assegurar educação de qualidade a estas pessoas (BRASIL, 2015).

A Lei de Inclusão vai além, e compete ao poder público assegurar, criar, desenvolver, implementar, incentivar, acompanhar e avaliar a "acessibilidade para todos os estudantes, trabalhadores da educação e demais integrantes da comunidade escolar às edificações, aos ambientes e às atividades concernentes a todas as modalidades, etapas e níveis de ensino" (BRASIL, 2015).

Como apresentado, o acesso e o uso das rotas, espaços e serviços dos ambientes de ensino não se limita apenas aos estudantes. Todos os integrantes que fazem parte do corpo da instituição de ensino - IE, ativamente ou de forma efêmera, precisam utilizar a instituição de maneira segura, confortável e autônoma, como objetiva a acessibilidade, assegurada pela norma brasileira - NBR 9050 (ABNT, 2015).

O objeto de estudo deste artigo é o Centro Universitário de Educação Superior da Paraíba UNIESP, localizado na cidade de Cabedelo-PB, às margens do km 14 da BR-230.

Uma das pesquisas desenvolvidas pelo Laboratório de Acessibilidade e Ergonomia - LacErgo é a Rota Acessível do UNIESP - instituição a qual o laboratório faz parte, tendo como objetivo desenvolver uma rota acessível dentro do campus, possibilitando um percurso autônomo e seguro de qualquer pessoa, independente da sua restrição de mobilidade. No entanto, a pesquisa ainda está em curso e este artigo tem como objetivo apresentar os resultados parciais da análise realizada até o momento, indicando o percurso e algumas soluções de deslocamento. 


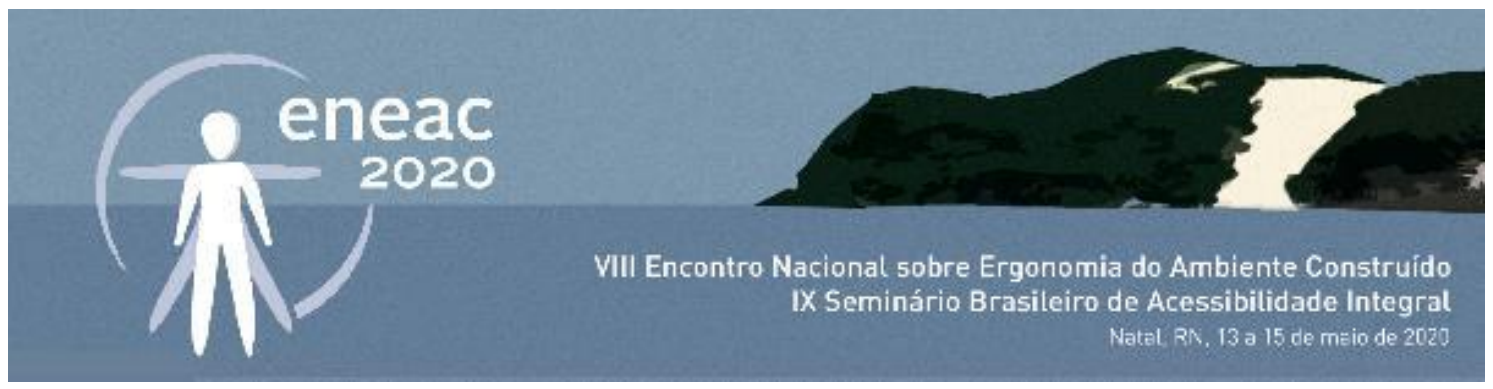

A estrutura desse artigo está dividida em: Introdução, referente a este capítulo, onde foi apresentada uma breve justificativa, o objeto de estudo e os objetivos; Fundamentação Teórica, que abordará conceitos que facilitam o entendimento geral do assunto aqui tratado; Metodologia, explicação do processo, dos métodos e a apresentação das ferramentas utilizadas durante a pesquisa; Resultados, estes são referentes atual fase do estudo da rota acessível realizada pelo LacErgo; por fim, serão apresentadas as considerações finais e as referências bibliográficas.

\section{FUNDAMENTAÇÃO TEÓRICA}

Nos termos do artigo 6, da constituição da república de 1988, são direitos do cidadão o acesso à moradia, ao trabalho, à educação, à saúde e ao lazer, independentemente de sexo, idade, cor, classe social ou limitação física, este é um direito garantido a todos (BRASIL, 1988).

Segundo Dischinger et. al.(2009) a acessibilidade é definida não só como a capacidade de chegar ou entrar em um lugar desejado, mas como a necessidade de compreender o que acontece nos espaços, de uma forma que possibilite se situar e se orientar neles, tornando mais fácil a orientação espacial nos ambientes com suas diferentes atividades, com autonomia, sem fazer perguntas pra chegar a sua finalidade, e buscando compreender aspectos como:

- orientação espacial: é o reconhecimento das características ambientais onde possibilita o indivíduo definir estratégias para o seu deslocamento e uso a partir do reconhecimento da identidade e funções do espaço;

- deslocamento: é a capacidade de se movimentar em percursos horizontais em ambientes internos e externos, livres de barreiras com segurança, independência e conforto;

- uso: refere-se à possibilidade efetiva de realizar atividades por todos de forma efetiva levando em conta as condições de uso dos espaços e equipamentos onde diversas características físicas dos equipamentos e mobiliários são levadas em consideração para permitir que sejam utilizados por todos;

- comunicação: é a possibilidade de troca de informações, e o alcance de informações através de suportes informativos.

Qualquer pessoa, em um determinado momento da vida, pode estar sujeita a certas limitações de mobilidade, decorrentes de acidentes, doenças ou pelo próprio processo de envelhecimento. Assim é necessária a inclusão por meio de mudanças sociais, culturais, políticas e de mudanças na configuração do ambiente físico, com foco na garantia de melhores condições de acessibilidade, possibilitando que os usuários consigam realizar atividades desejadas sem qualquer impedimento, independentemente de sua restrição de mobilidade (DISCHINGER; BINS ELY; PIARDI, 2012).

Uma das formas de possibilitar um fácil acesso aos espaços físicos é utilizando uma rota acessível, que consiste em um trajeto contínuo, desobstruído e sinalizado, que conecta os ambientes externos e internos de espaços e edificações, e que pode ser utilizada de forma 


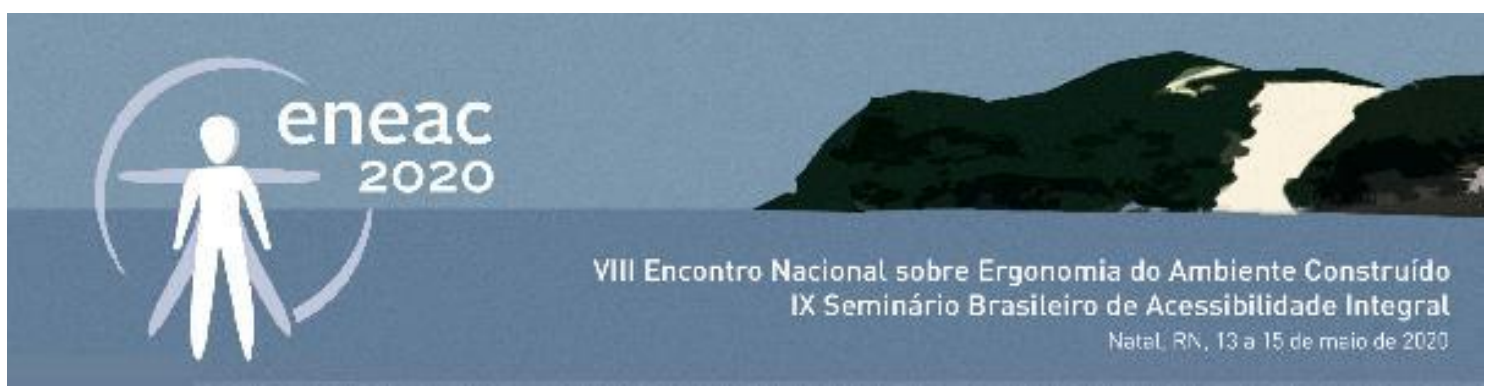

autônoma e segura por todas as pessoas. A rota acessível externa incorpora estacionamentos, calçadas, faixas de travessias de pedestres (elevadas ou não), rampas, escadas, passarelas e outros elementos da circulação. A rota acessível interna incorpora corredores, pisos, rampas, escadas, elevadores e outros elementos da circulação (ABNT, 2015).

Os espaços físicos de uma universidade são dotados de uma variedade de funções e de usuários, apresentando características de uma pequena cidade, com configurações espaciais diversificadas, onde suas necessidades, conforto e segurança não se limitam ao corpo universitário, mas também a comunidade. A acessibilidade espacial, é algo pouco discutido no ensino superior, já no ensino fundamental o processo de acessibilidade e inclusão já reflete em transformações espaciais (DISCHINGER et. al., 2008).

Avanços já foram feitos no sentido de melhorar a comunicação entre professores e alunos, com diversos métodos como material didático em versões em Braille ou áudio, a utilização de softwares para a leitura de textos digitais e a presença de um intérprete da linguagem brasileira de sinais - Libras. Não basta as práticas pedagógicas ou métodos específicos de ensino, mesmo com a garantia por lei da inclusão, essas práticas por si só não são efetivas para uma inclusão efetiva, outros diversos fatores também influenciam, como a formação de profissionais adequados e as condições adequadas de acesso e uso destes espaços físicos nas universidades (DISCHINGER et. al., 2008).

\section{METODOLOGIA}

Esta pesquisa faz parte do LacErgo, laboratório coordenado pelo professor Júlio César Felix de Alencar Fernandes. A escolha do objeto de pesquisa se deu a partir da demanda provocada pelo próprio UNIESP, por meio do Núcleo de Acessibilidade - NACE da instituição.

A análise da rota acessível no campus do UNIESP teve início no ano de 2017 com o levantamento físico e fotográfico dos pontos de interesse da rota, utilizando trenas de 5 metros para verificar das dimensões de interesse e celulares para realizar as fotografias. Neste mesmo período foram realizados passeios acompanhados com pessoas com deficiência com o intuito de compreender como as pessoas com limitações de mobilidade se comportavam, estes caminhavam de forma autônoma acompanhados dos pesquisadores, que analisavam todo o desempenho durante o percurso.

Durante o ano de 2018 pouco foi realizado a respeito desta pesquisa, visto que o LacErgo estava priorizando outras áreas de interesse.

Em 2019.2 a rota acessível voltou a ser um dos focos do laboratório, deste momento em diante foram realizados novos levantamentos físicos e fotográficos, com o auxílio de trenas e celulares.

A coordenadora do curso de Design de Interiores do UNIESP disponibilizou a planta baixa digital atualizada da instituição. Em seguida, foi possível desenvolver, in loco, um estudo do fluxo dos pedestres, por meio de uma análise observacional, priorizando uma rota onde o deslocamento das pessoas era mais intenso. 


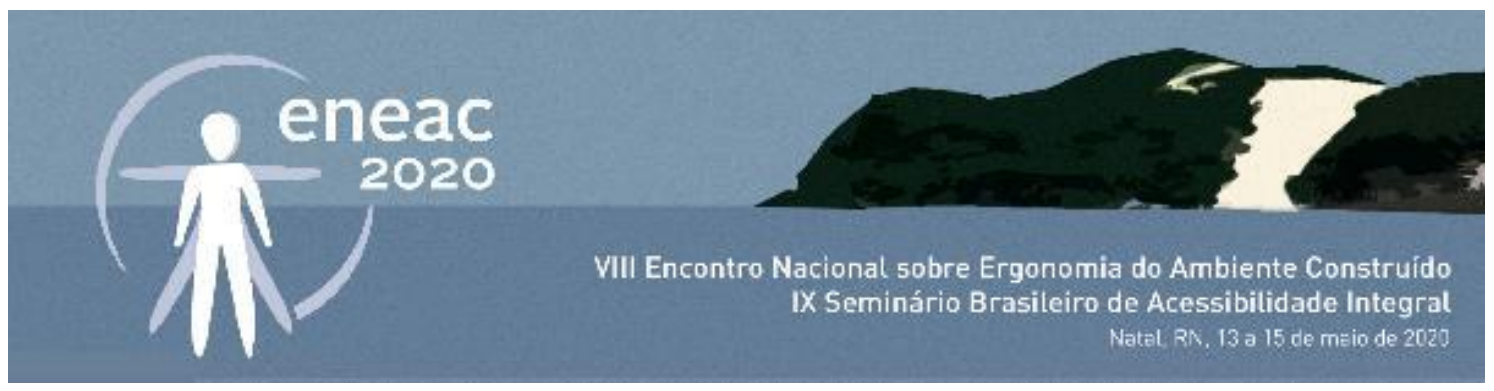

Em seguida, o coordenador do laboratório e os pesquisadores definiram a melhor rota, com base nas pesquisas anteriores. Esta etapa foi finalizada com a edição da planta baixa original da IES, utilizando o software AutoCad e representando em vermelho (conforme Figura 1) toda a rota acessível.

Por fim, foram editadas fotografias do campus com o intuito de mostrar mais claramente como será a rota acessível após a execução do projeto. A pesquisa atualmente passará para a fase de aprovação pela diretoria do UNIESP, para prosseguir com detalhamento de um possível projeto executivo.

\section{RESULTADOS}

Com base nas discussões levantadas, fora elaborado uma sugestão de rota acessível para uma instituição de ensino superior (IES) na cidade de Cabedelo-PB. Os estudos aqui apresentados foram desenvolvidos pelo Laboratório de Acessibilidade e Ergonomia (Lacergo) do Centro Universitário UNIESP. A instituição de ensino não possui um caminho uniforme que proporcione autonomia para uma pessoa com deficiência. $\mathrm{O}$ objetivo da proposta foi que, com apenas uma rota, atendesse a todos os edifícios. Assim, a pessoa que chegasse à instituição, teria uma rota acessível para todos os pontos do campus.

Para iniciar o projeto da rota acessível foi traçado um roteiro com etapas a serem seguidas. A primeira etapa foi a de levantamentos físicos, de campo e de dados. Assim, a equipe do laboratório visitou o objeto de estudo, onde foram elaborados esboços com dimensões e fora solicitada a planta baixa de todo o campus. Ainda no levantamento de campo, pessoas com diversas deficiências foram convidadas a realizar trajetos desde a entrada da IES até algum edifício. Com essa experiência, foi possível observar as dificuldades mais presentes e as correções necessárias, com base nos parâmetros normativos vigentes e na vivência das pessoas com deficiência.

Após a etapa de levantamentos, foi traçado o conceito de intervenção, estabelecidas as diretrizes que serão adotadas e realizado um estudo de fluxos para distribuição dos usuários entre os edifícios. Com o estudo de fluxos realizado, definiu-se uma melhor rota e foi iniciado o processo de representação bidimensional, utilizando da planta disponibilizada pela IES. Na Figura 1, é apresentada um mapa do objeto de estudo com os edifícios na cor cinza e a rota acessível sugerida, destacada na cor vermelha. 


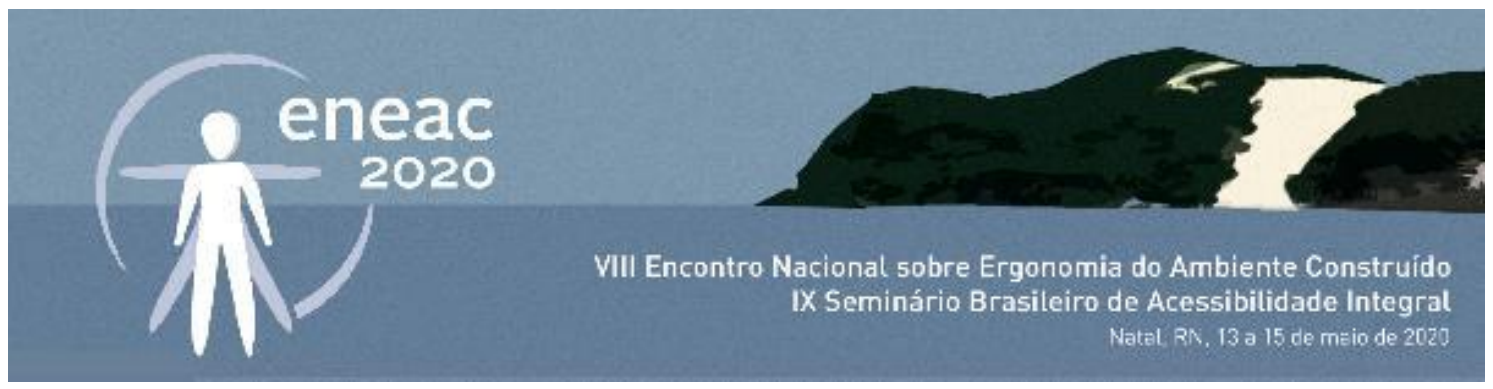

Figura 1 - Mapa do UNIESP com rota acessível destacada em vermelho

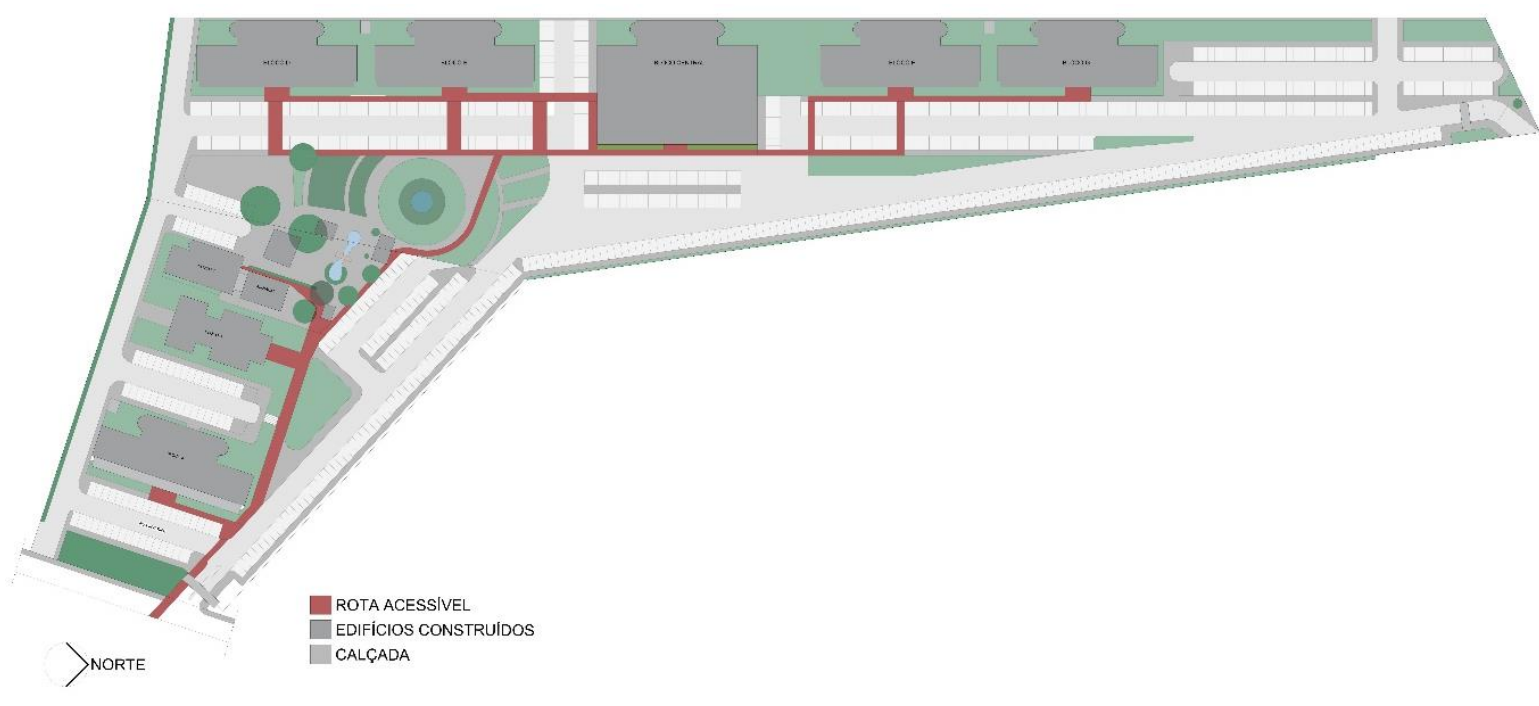

Fonte: adaptado de UNIESP (2019)

A IES em estudo possui oito edifícios construídos. Tem um único acesso para pedestres localizado em uma via auxiliar à rodovia federal BR-230. Na parte externa à instituição encontram-se alguns problemas. $\mathrm{O}$ usuário pode chegar em diferentes modais, a pé, por transporte público, carro particular, bicicleta, motocicleta ou de transporte fretado. Os modais a que se destinam a proposta da implantação de uma rota acessível se direcionam aos provenientes de transporte público e a pé. Todos os outros modais conseguem adentrar à IES e desembarcar diretamente no edifício de interesse.

Apesar de haver um ponto de transporte público em frente ao portão da IES, a travessia da via é dificultada pois não possui uma faixa de pedestres elevada, conforme Figura 2. Para solucionar o problema, que é de ordem pública e por este motivo não se encontra representada nos esquemas aqui apresentados, sugere-se a construção de uma faixa de pedestres elevada ao nível da calçada, permitindo uma travessia segura e acessível, além de funcionar como redutor físico de velocidade para os veículos automotores. 

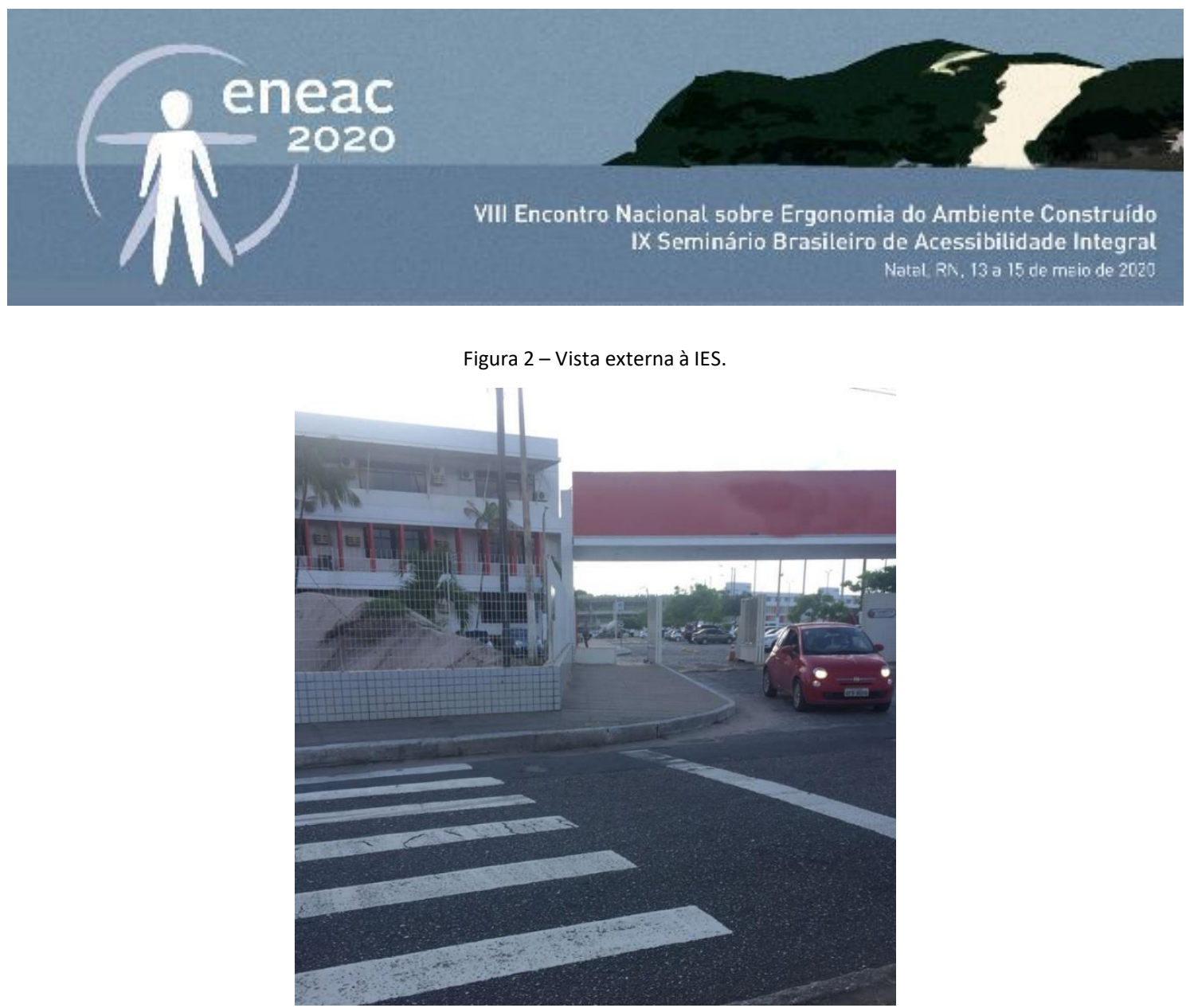

Fonte: acervo LacErgo

Na proposta, todo o trajeto da rota acessível é destacado com piso vermelho para facilitar a identificação visual do usuário, além de guiá-lo aos edifícios. No início do trajeto é proposta a implantação de um mapa tátil para localização do usuário. O material proposto para o revestimento do passeio é um bloco cimentício retangular na cor vermelha e assentado de forma intertravada.

Na Figura 3 é possível identificar o portão de entrada da IES, onde a travessia da via carroçável interna é feita por uma faixa de pedestres. Ainda na figura, o triângulo amarelo é apresentado em uma vista aproximada do mapa para ilustrar o ponto do observador da fotografia apresentada. Apesar de possuir rampa implantada em ambas as calçadas, o material da via é trepidante e irregular. Assim, utilizou-se da mesma estratégia adotada para a travessia da via externa, a implantação de uma faixa de pedestres elevada ao nível da calçada, conforme a imagem apresenta uma foto inserção. 


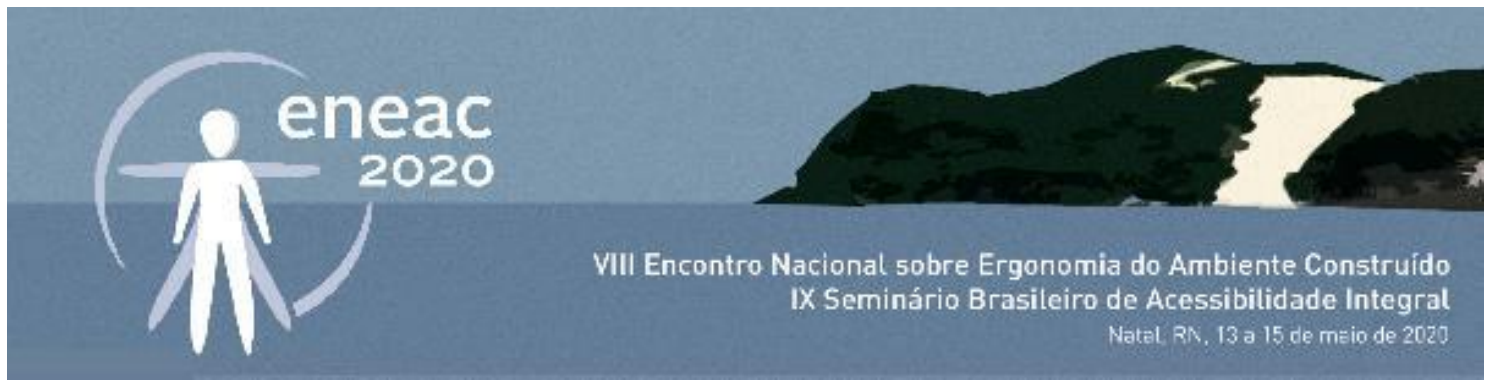

Figura 3 - Vista do portão de entrada da IES/Vista com foto inserção da rota acessível.

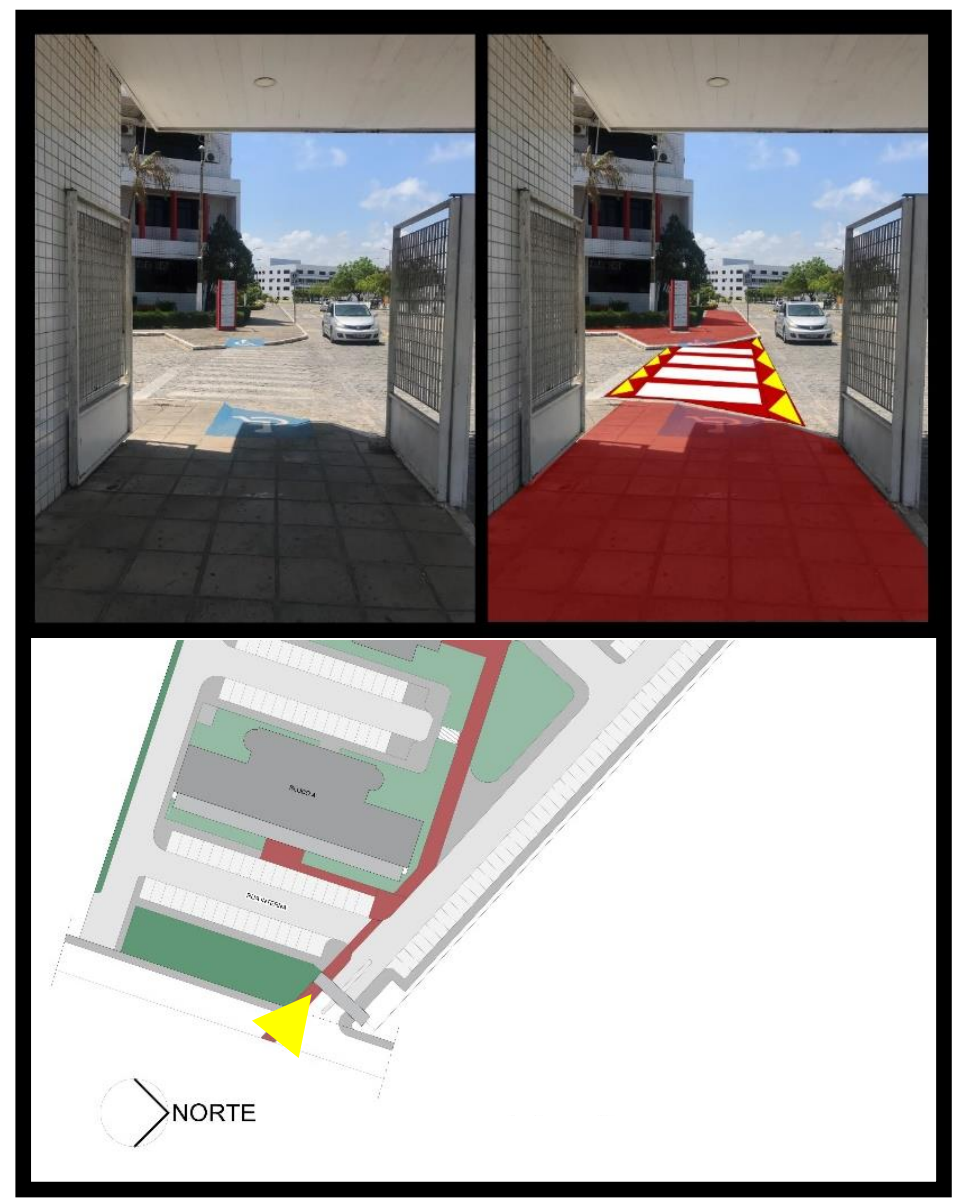

Fonte: acervo LacErgo

Em alguns trechos da rota acessível, será necessário apenas adaptar o piso, evitando desníveis, e aplicar a cor vermelha. O vermelho foi utilizado por se tratar de uma cor de destaque e estar presente na identidade visual do objeto de estudo. É importante que em todo o trajeto da rota acessível não possua obstáculos verticais abaixo de $2,10 \mathrm{~m}$ de altura e desníveis como tampas de caixas de inspeção. A inserção do piso tátil na cor cinza, para facilitar sua identificação, também se faz necessária ao longo de toda a rota. Estes cuidados são necessários, conforme orientação da NBR 9050, para proporcionar segurança e fluidez ao trânsito de pessoas.

Na Figura 4, retirada da NBR 9050 (ABNT, 2015), apresenta-se uma imagem onde são classificadas as três faixas de um passeio com suas respetivas dimensões recomendadas. As faixas são divididas em de serviço com $0,70 \mathrm{~m}$ recomendados; faixa livre, com 1,20m; faixa de acesso, sem dimensão recomendada. Ainda é constatada na imagem a altura livre mínima de 2,10m para obstáculos verticais, conforme falado anteriormente. 


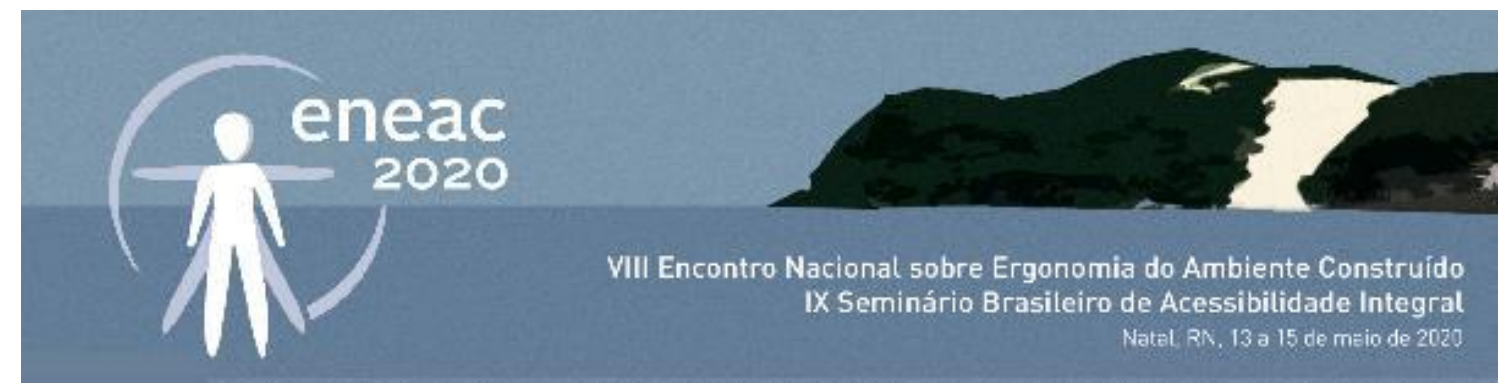

Figura 4 - Dimensões passeio

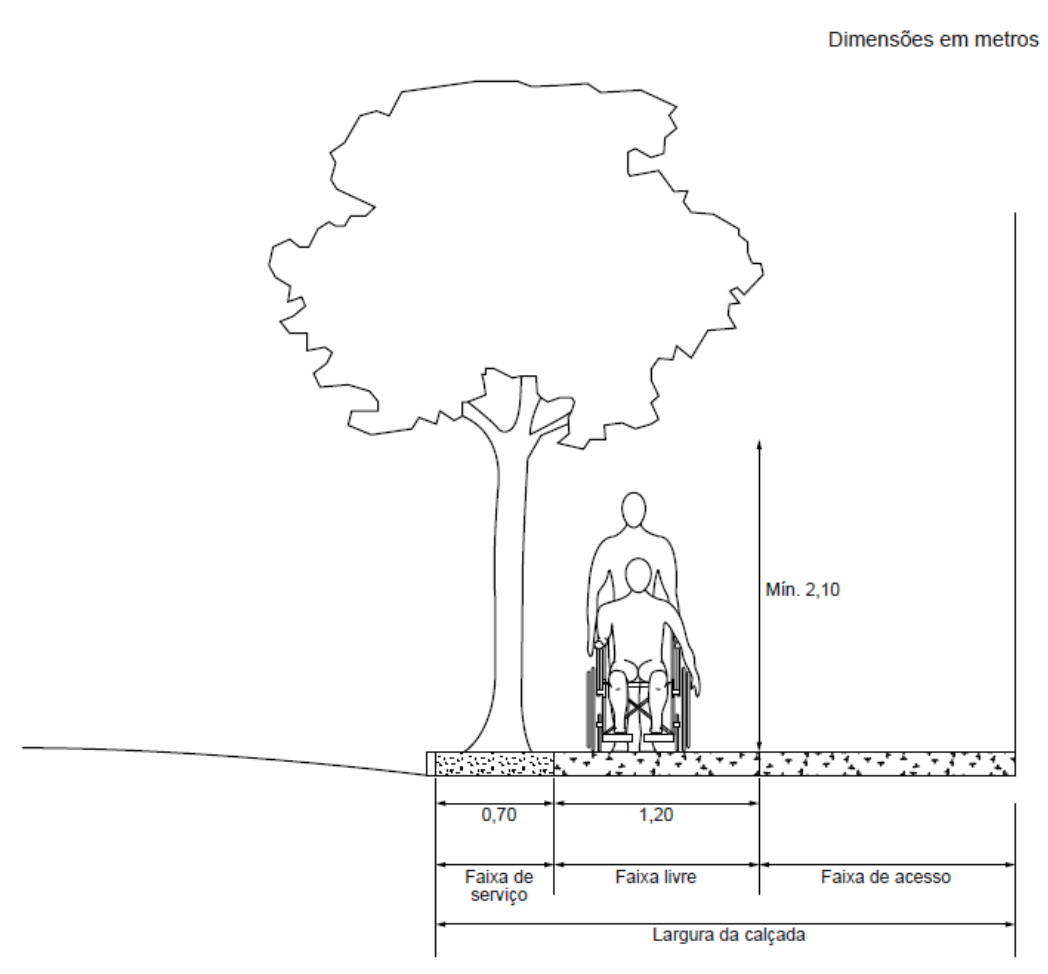

Fonte: NBR9050/ABNT (2015).

A faixa de serviço é utilizada para sinalizações verticais, tais como placas de estacionamento, mapas ou qualquer outro equipamento. Também é utilizada para implantação de vegetação e luminárias. Já a faixa livre é destinada à livre circulação de pedestres. A faixa de acesso, é destinada a ser um elemento de transição, saindo do limite do público e entrando no privado. A faixa de acesso é utilizada para quem está chegando ao passeio ou saindo dele, de modo que possa estacionar-se sem impedir o fluxo da faixa livre.

Na Figura 5, é destacada toda a área de circulação horizontal entre os edifícios. À esquerda a fotografia realizada no local e à direita uma foto inserção da rota acessível pintada em vermelho. Apesar das dimensões limitadas, utilizou-se uma faixa de serviço para a disposição dos equipamentos necessários e uma faixa livre de circulação. A faixa de acesso, dado o seu caráter opcional e o limite de dimensão pré-existente, não fora utilizada. 


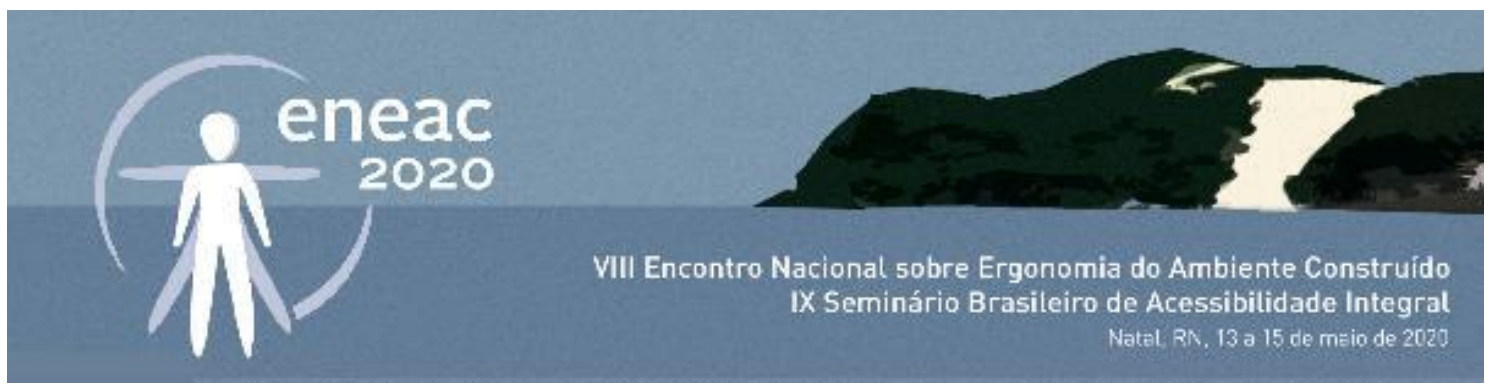

Figura 5 - Vista entre edifícios

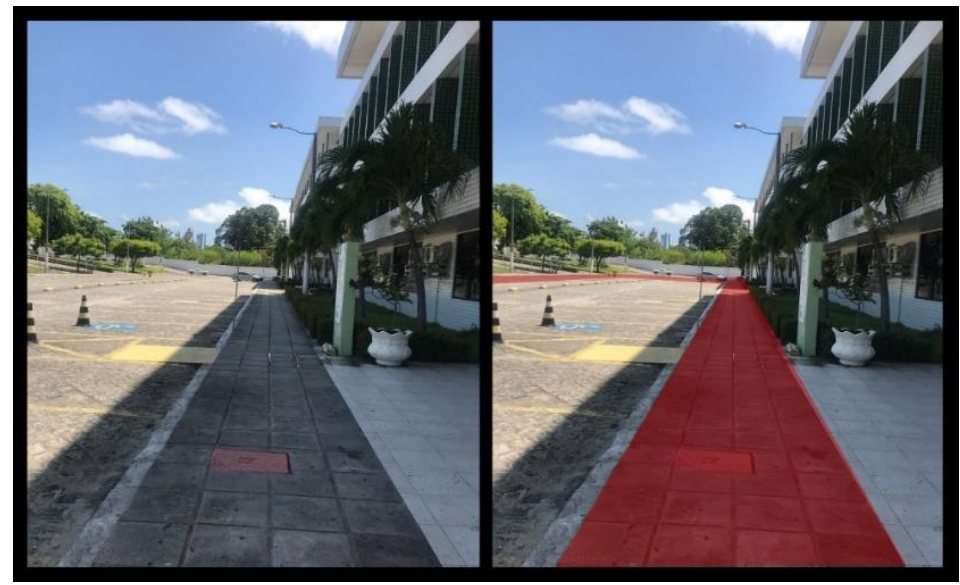

Fonte: acervo LacErgo

Na Figura 6, novamente uma fotografia à esquerda da situação atual onde possui uma via carroçável interna interrompendo o passeio. Com a existência de guias rebaixadas que daria acesso de um lado ao outro e a presença de uma faixa de pedestre, sugere-se apenas que ela seja elevada ao nível do passeio, evitando que o pedestre desça um nível, já que o material trepidante do calçamento não é adequado à circulação recomendada pela NBR 9050.

Figura 6 - Travessia entre edifícios.

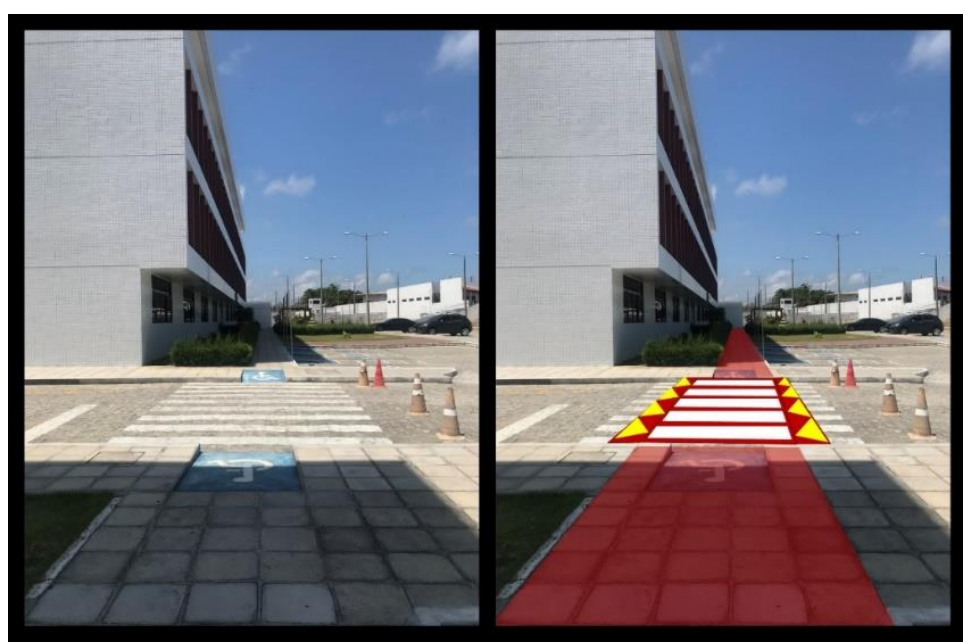

Fonte: acervo LacErgo

Na Figura 7, a ilustração demonstra que não será em todos os momentos que a rota acessível se apossará de todo o passeio já existente. É importante destacar que a rota é única, possuindo apenas algumas ramificações. Assim, na imagem, é possível notar que existe um material trepidante no piso, o que dificulta a circulação de pessoas com deficiência, sobretudo usuários de cadeira de roda. Assim, sugere-se aplica apenas em uma parte do passeio, respeitando as dimensões já vistas. 

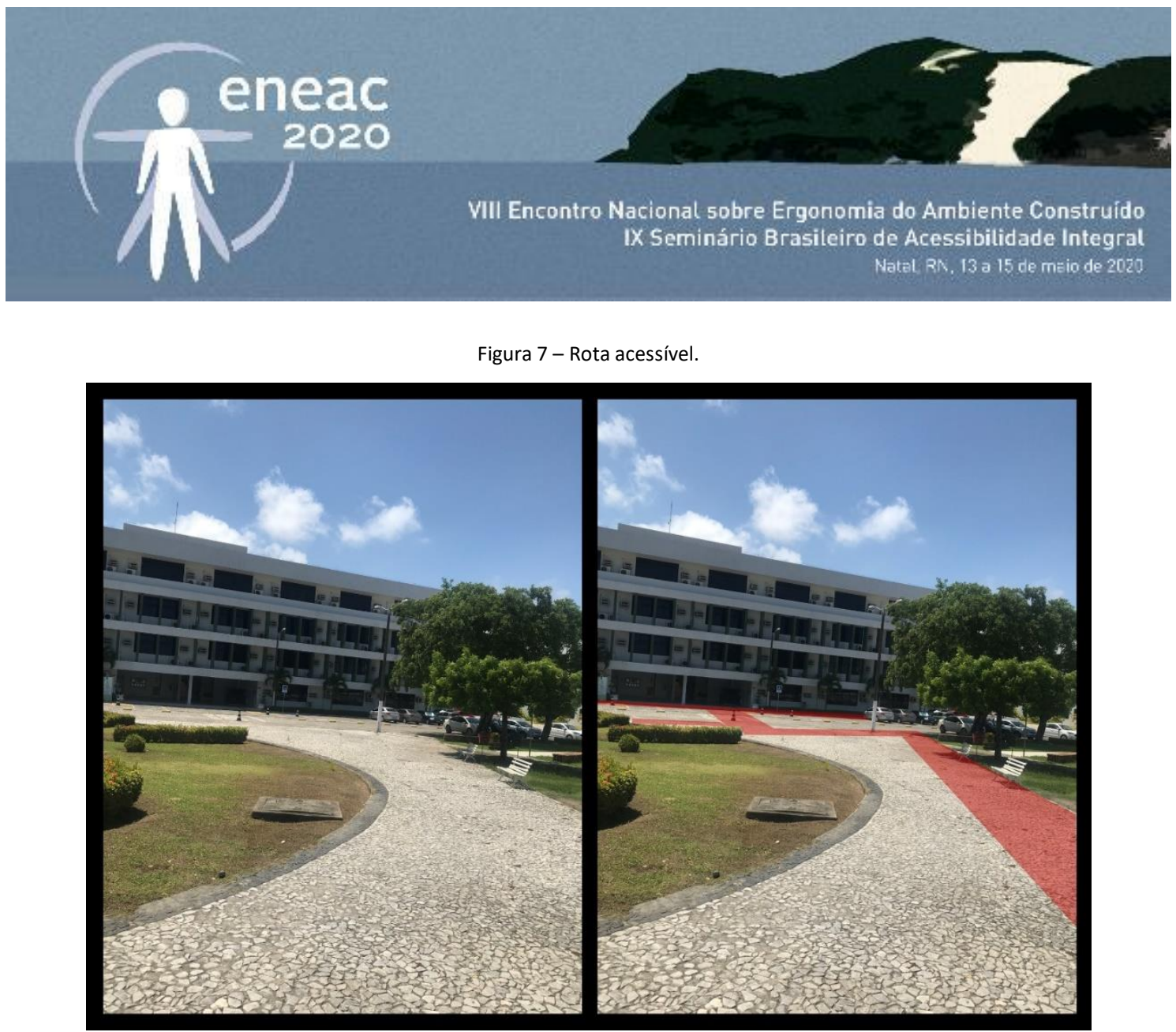

Fonte: acervo LacErgo

Por fim, destaca-se que para o planejamento da rota acessível seguiu-se um plano com etapas delimitadas e foi priorizada a acessibilidade para o usuário de uma forma que seja de fácil implantação, com o menor impacto na estrutura vigente. Atualmente o plano da rota acessível encontra-se em etapa de apresentação à direção do campus para dar início à etapa de projeto executivo.

\section{CONSIDERAÇÕES FINAIS}

A rota acessível externa é um importante elemento para ser aplicado, sobretudo em complexos de edifícios, como centros universitários. Com a função de guiar com segurança a pessoa com deficiência ou não até o seu local de destino, a rota vem recebendo cada vez maior visibilidade, sobretudo com a adoção de leis municipais para sua aplicação em equipamentos públicos.

Durante a pesquisa para implantação da rota acessível no objeto de estudo, constatou-se a real necessidade dos elementos descritos pela norma de acessibilidade NBR 9050. A depender de cada edifício, a rota pode ser implantada sem grandes modificações, sobretudo onde há áreas livres, como foi o caso do objeto de estudo. Assim, a facilidade de execução pode vir a estimular outras entidades a aplicá-la. 


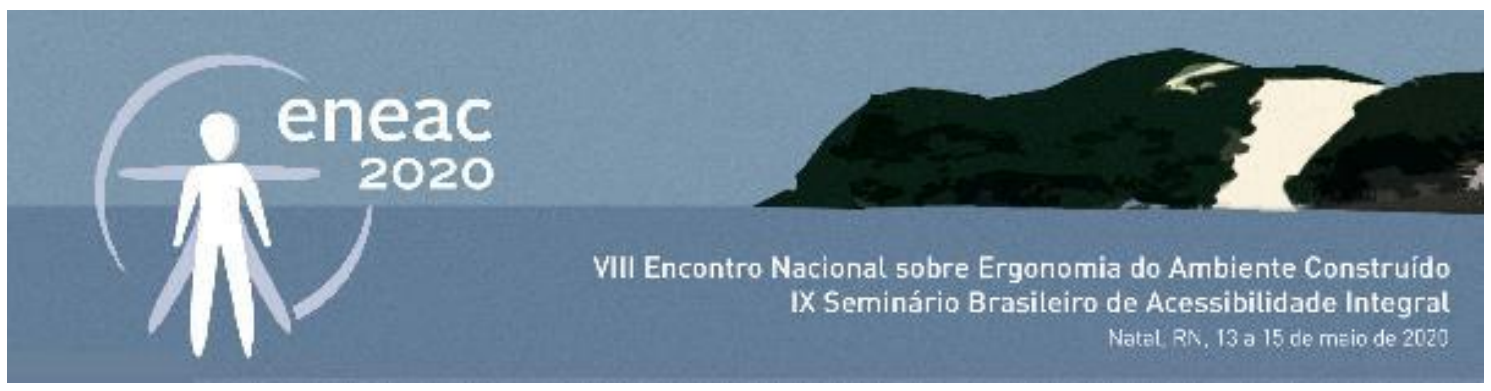

\section{REFERÊNCIAS BIBLIOGRÁFICAS}

ASSOCIAÇÃO BRASILEIRA DE NORMAS TÉCNICAS. NBR 9050: Acessibilidade a edificações, mobiliário, espaço e equipamentos urbanos. 3 ed. Rio de Janeiro: ABNT, 2015. 148 p.

BRASIL. Constituição (1988). Constituição da República Federativa do Brasil. Disponível em: <http://www.planalto.gov.br/ccivil_03/Constituicao/Constituicao.htm>. Acesso em: 10 jan. 2020.

BRASIL. Lei № 13.146, de 6 de julho de 2015 - Lei Brasileira de Inclusão da Pessoa com Deficiência Estatuto da Pessoa com Deficiência. Disponível em: <http://www.planalto.gov.br/ccivil_03/_ato2015-2018/2015/lei/l13146.htm>. Acesso em: 28 jan. 2020.

DISCHINGER, Marta; ELY, Vera Helena Moro Bins; PIARDI,Sonia Maria Demeda Groisman, Pomovendo acessibilidade espacial nos edifícios públicos: Programa de Acessibilidade ás Pessoas com Deficiência ou Mobilidade Reduzida nas Edificações de Uso Público; PIARDIMPSC- Ministério Público de Santa Catarina, Florianópolis-SC, Brasil-1a Edição2012.

DISCHINGER, Marta; MATTOS, Melissa Laus; BRANDÃO, Milena de Mesquita; ELY, Vera Helena Moro Bins, Orientarse em campi universitários no Brasil: condição essencial para a inclusão; PONTO DE VISTA, Florianópolis, n. 10, p. 39-64, 2008.

DISCHINGER, Marta; ELY, Vera Helena Moro Bins; BORGES, Monna Michelle Faleiros da Cunha; MANUAL DE ACESSIBILIDADE ESPACIAL PARA ESCOLAS: O direito à escola acessível; Ministério da Educação,Secretaria de Educação Especial, BRASIL- 2009. 